\title{
GCU
}

Glasgow Caledonian

University

University for the Common Good

\section{Prevalence of fatigue and its association with clinical features in progressive and non- progressive forms of Multiple Sclerosis}

Rooney, Scott; Wood, Les; Moffat, Fiona; Paul, Lorna

Published in:

Multiple Sclerosis and Related Disorders

DOI:

10.1016/j.msard.2019.01.011

Publication date:

2019

Document Version

Author accepted manuscript

Link to publication in ResearchOnline

Citation for published version (Harvard):

Rooney, S, Wood, L, Moffat, F \& Paul, L 2019, 'Prevalence of fatique and its association with clinical features in progressive and non-progressive forms of Multiple Sclerosis', Multiple Sclerosis and Related Disorders, vol. 28, pp. 276-282. https://doi.org/10.1016/j.msard.2019.01.011

\section{General rights}

Copyright and moral rights for the publications made accessible in the public portal are retained by the authors and/or other copyright owners and it is a condition of accessing publications that users recognise and abide by the legal requirements associated with these rights.

Take down policy

If you believe that this document breaches copyright please view our takedown policy at https://edshare.gcu.ac.uk/id/eprint/5179 for details

of how to contact us. 


\title{
Prevalence of fatigue and its association with clinical features in progressive and non-progressive forms of Multiple Sclerosis
}

\author{
Scott Rooney, ${ }^{\mathrm{a}}$ Dr Les Wood, ${ }^{\mathrm{a}}$ Dr Fiona Moffat, ${ }^{\mathrm{b}}$ Professor Lorna Paul, ${ }^{\mathrm{a}}$ \\ ${ }^{a}$ School of Health and Life Sciences, Glasgow Caledonian University, Glasgow, Scotland, \\ UK; ${ }^{b}$ NHS Forth Valley, Scotland, UK.
}

\section{Corresponding Author}

Scott Rooney, School of Health and Life Sciences, Glasgow Caledonian University, Cowcaddens Road, Glasgow, G4 0BA. Email address: scott.rooney@gcu.ac.uk 


\begin{abstract}
Background: Fatigue is a complex and disabling symptom of Multiple Sclerosis (MS); however, there is conflicting evidence of the relationship between fatigue and clinical features of MS. Furthermore, few studies have considered these relationships specifically in a progressive MS population.
\end{abstract}

Aims: (1) estimate the prevalence of self-reported fatigue in people with MS; (2) evaluate the relationship between fatigue severity/impact and clinical features of MS; (3) compare the prevalence of fatigue, and the strength of relationship between fatigue severity/impact and clinical features of MS in progressive and non-progressive forms of MS.

Methods: An online survey was conducted to measure the severity (Fatigue Severity Scale (FSS)) and impact of self-reported fatigue (Modified Fatigue Impact Scale) in people with MS. The survey also contained questionnaires related to disability, quality of life, MS impact, anxiety and depression, cognition, and sleep quality.

Results: 412 people responded to the survey, of which $68.7 \%$ reported having fatigue (FSS $\geq 5$ ). The prevalence of fatigue was significantly higher in participants with progressive MS (81\%) in comparison to those with non-progressive forms of MS $(64 \%, p=0.01)$. Fatigue severity and impact were associated with quality of life, MS impact, anxiety, depression, cognition, and sleep quality in both progressive and non-progressive MS populations $(\mathrm{p}<0.05)$. However, fatigue severity $(\mathrm{r}=0.335)$ and impact $(\mathrm{r}=0.391)$ were correlated with disability only in participants with non-progressive MS.

Conclusion: Fatigue was more prevalent amongst participants with progressive MS. In addition, higher fatigue severity and impact were associated with greater physical, cognitive, and psychological impairment, although the strength of association between these outcomes was generally similar regardless of the type of MS.

Key words: Multiple Sclerosis; fatigue; depression; anxiety; cognition; sleep quality 


\section{Introduction}

Fatigue is a complex and multifactorial symptom of Multiple Sclerosis (MS) which can be defined as "a subjective lack of physical and/or mental energy that is perceived by the individual or caregiver to interfere with usual and desired activities" [1]. It is often regarded as the most debilitating symptom of MS which impacts upon cognitive, psychological, and physical functioning [2], while also leading to reduced quality of life and unemployment $[3,4]$. Estimates of fatigue prevalence range between $52 \%-88 \%$, making it one of the most common symptoms of MS [5-13]. However, differences in study populations and outcome measures, and differences in the methods used to identify people with or without fatigue explain the large variation in the reported prevalence of fatigue between studies.

While the exact pathophysiological mechanisms of MS-fatigue remain unknown, there is evidence to suggest that fatigue is a direct consequence of the primary pathological mechanisms of MS including inflammation and neurological damage [14]. In addition, secondary mechanisms independent of MS pathophysiology such as depression or disability may contribute to the development of fatigue [15]. However, studies investigating the association of fatigue with concomitant clinical and demographic features have presented conflicting results. For example, several cross-sectional $[8,13,16,17]$ and longitudinal studies [18-21] have demonstrated an association between fatigue and depression, while other studies have demonstrated that fatigue occurs independently of depression [6, 22, 23]. Similarly, there is limited consensus regarding the relationship between fatigue and disability $[8,11,13,23,24]$, and fatigue and demographic variables such as age, sex, and disease duration $[6,9,23,25]$. Furthermore, few studies have considered the relationship between fatigue and sleep quality [26-28], or cognition [17,29] - symptoms which are common in MS $[30,31]$, and have been suggested to contribute to the development of fatigue [14].

Although fatigue is more prevalent in progressive forms of MS [10, 19, 23], few studies have considered the association between fatigue and relevant clinical features specifically in progressive MS populations (secondary progressive MS (SPMS) and primary progressive MS (PPMS)). Therefore, further work is required to understand which clinical and demographic 
features are associated with fatigue to inform the design and evaluation of fatigue management interventions for people with progressive MS. Hence, this study aims to: (1) estimate the prevalence of self-reported fatigue in people with MS; (2) evaluate the relationship between fatigue severity and impact and clinical features of MS and; (3) compare the prevalence of fatigue and the relationships in (2) in progressive and non-progressive MS.

\section{Methods}

\subsection{Design and participant recruitment}

This cross-sectional study collected data using an online survey made available for one month between May 30th-June 30th 2018. The open-access survey was designed using RedCap software v6.15 [32] and was accessed via a link distributed online to potential participants through information shared by national and international MS charities and organisations based in the UK, USA, and Australia. Prior to accessing the survey, participants were required to confirm they had a medical diagnosis of MS and were aged 18 years or older. Participants self-reported demographic information (including MS type and disability using the Patient Determined Disease Steps (PDDS)) [33, 34], and completed a series of patient-reported outcome measures related to fatigue, MS impact, quality of life, depression and anxiety, cognition, and sleep. The survey took approximately 30-40 minutes to complete, and participants were allowed to save responses and return to the survey at a later time. Ethical approval for this study was obtained from Glasgow Caledonian University School of Health and Life Sciences Ethics Committee.

\subsection{Outcome measures}

\subsubsection{Fatigue}

Fatigue severity was assessed using the Fatigue Severity Scale (FSS). The FSS is a sevenpoint ordinal scale where participants rate the severity of fatigue in response to nine items, with total scores ranging between 0-7 [35]. The FSS has demonstrated moderate test-retest reliability and high precision in MS populations [24, 36, 37], and has strong internal 
consistency [38]. In line with previous studies, participants that scored $\geq 5$ on the FSS were classified as fatigued $[8,10,17-19,21,25]$.

Fatigue impact was measured using the Modified Fatigue Impact Scale (MFIS). The MFIS is a multidimensional scale that evaluates the impact of fatigue on physical, cognitive, and psychosocial domains [25]. The MFIS contains 21 items (nine physical, ten cognitive, and two psychosocial) with a five-point ordinal scale (maximum score of 84), and requires participants to recall the impact of fatigue, with higher scores indicating a greater impact of fatigue [25]. The MFIS is widely used in MS populations, and has strong validity and testretest reliability [24, 36, 37, 39].

\subsection{2. $M S$ impact}

MS impact was assessed using the MS Impact Scale-29 (MSIS-29) version one, a valid and reliable disease specific questionnaire which assesses the physical and psychological impact of MS over 29 items using an ordinal scale [40-42]. Physical and psychological subscale scores range between 20-100 and 9-45 respectively, with higher scores indicating greater impact of MS.

\subsubsection{Quality of life}

Quality of life was assessed using the EQ-5D-3L, which consists of five domains - mobility, self-care, usual activities, pain/discomfort, and anxiety/depression - and generates a health index $\left(E Q-5 D_{\text {index }}\right)$ with a maximum score of 1 indicating 'full health' [43]. The weighted health index was calculated using the UK value set [44]. The EQ-5D-3L also captures selfreported health status (EQ-5D $\mathrm{D}_{\text {status }}$ ) using a visual analogue scale ranging between 0 (worst imagined health state) and 100 (highest health state).

\subsubsection{Anxiety and depression}


Anxiety and depression were measured using the Hospital Anxiety and Depression Scale (HADS). The HADS consists of separate anxiety and depression scales that are comprised of seven items - scores range between 0-21 with higher scores indicating greater severity of anxiety or depression [45]. The validity of the HADS has been demonstrated in MS populations [46].

\subsubsection{Cognition}

Cognition was assessed using the MS Neuropsychological Screening Questionnaire (MSNSQ) - a valid screening tool for cognitive dysfunction in people with MS which has been shown to correlate with Symbol Digit Modalities Test scores [47-49]. Participants rate the impact and severity of problems with attention, memory, processing speed, emotional control, and social skills across 15 items using an ordinal scale [47]. Scores range from 0-60, with higher scores indicating greater cognitive dysfunction.

\subsubsection{Sleep quality}

Sleep quality was assessed using the Pittsburgh Sleep Quality Index (PSQI), a 19-item questionnaire comprised of seven components: subjective sleep quality, sleep latency, sleep duration, habitual sleep efficiency, sleep disturbances, use of sleeping medication and daytime dysfunction during the previous month [50]. Scores range from 0-21, with higher scores indicating poorer sleep quality. Validity of the PSQI has been demonstrated in clinical populations [51], and the PSQI has been used in other MS studies [17, 24].

\subsection{Data analysis}

Data analysis was performed using IBM SPSS v23 (IBM Corporation, Armonk, NY, USA). Survey responses of participants who provided complete demographic information and FSS scores were included in the data analysis, and missing data were excluded from subsequent analysis using pairwise deletion. The prevalence of fatigue (percentage of people who reported FSS $\geq 5$ ), mean questionnaire scores, and participant demographics were compared 
between those with progressive and non-progressive forms of MS (relapsing-remitting MS (RRMS), Benign MS, or an unknown form of MS) using Chi-square tests for categorical variables and unpaired t-tests for continuous variables as data were normally distributed according to the Shapiro-Wilk statistic. Pearson correlation coefficients were used to assess the relationship of the FSS and MFIS with questionnaire responses (MSIS-29, EQ-5D, HADS, MSNSQ, PSQI) and demographic variables (disability, disease duration, age) correlation coefficients $<0.3$ were interpreted as weak, $\geq 0.3$ to $<0.7$ as moderate, and $\geq 0.7$ as strong [52]. Subsequently, correlation coefficients were compared between people with progressive non-progressive MS using z values derived from Fisher's transformation [53]. Finally, two separate multiple linear regression analyses were performed using FSS (fatigue severity) and MFIS (fatigue impact) as the dependent variables for both progressive MS and non-progressive MS populations. Independent variables (FSS/MFIS (total score), age, time

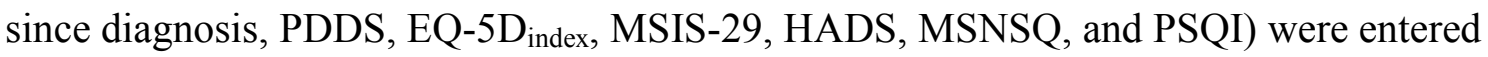
using stepwise backwards elimination methods with probability values of $\leq 0.05$ for variable entry and $\geq 0.10$ for variable removal. For all tests, a significance level of $p<0.05$ was used.

\section{Results}

\subsection{Demographic data and fatigue prevalence}

Of the 498 people who participated in the survey, 412 (83\%) provided full demographic data and FSS scores and were included in the analysis (Table 1). In total 308 participants (75\%) provided complete survey responses. 111 (27\%) participants reported having a progressive form of MS (SPMS = 74, PPMS = 37), whereas $301(73 \%)$ reported having a non-progressive form $($ RRMS $=291$, benign $M S=2$, unknown type $=8$ ). Participants were mostly female $(81.3 \%)$ and had a mean (SD) age of 46 years (11.5) and time since diagnosis of 9.6 years (8.6). People with progressive MS were significantly older $(\mathrm{p}<0.001)$, had a longer time since diagnosis $(\mathrm{p}<0.001)$, reported higher levels of disability $(\mathrm{p}<0.001)$, and had a higher proportion not in employment $(\mathrm{p}<0.001)$ in comparison to participants with non-progressive MS (Table 1).

\section{Table 1 (near here)}


The prevalence of fatigue was significantly higher amongst participants with progressive MS $(81.1 \%, 95 \% \mathrm{CI}=72.8-87.3)$ compared to the non-progressive MS population $(64.1 \%, 95 \%$ $\mathrm{CI}=58.6-69.3$ ) (Table 2). In addition, participants with progressive MS reported greater fatigue severity $(\mathrm{FSS}=5.6 \pm 1.3, \mathrm{p}=0.012)$, and greater physical $($ MFIS $($ physical $)=27.8 \pm 6.1$, $\mathrm{p}<0.001)$ and psychosocial impact of fatigue (MFIS (psychosocial) $=5.7 \pm 1.8, \mathrm{p}=0.009$ ). However, mean MFIS (total) $(\mathrm{p}=0.149)$ did not differ between participants with progressive or non-progressive MS. Across the other outcome measures, participants with progressive MS reported lower quality of life $(\mathrm{p}<0.001)$, and higher depression $(\mathrm{p}<0.001)$ and physical impact of MS ( $\mathrm{p}<0.001)$ (Table 2). There were no differences between the progressive MS and non-progressive MS populations in cognition (MSNSQ, $p=0.2$ ), impact of fatigue on cognition (MFIS (cognition), $\mathrm{p}=0.371)$, psychological impact of MS ( $\mathrm{p}=0.924)$, anxiety ( $\mathrm{p}$ $=0.667)$ and sleep quality $(\mathrm{p}=0.416)$.

Table 2 (near here)

\subsection{Correlation of fatigue severity with clinical variables}

In the total study population, fatigue severity (FSS) was moderately correlated with fatigue impact (MFIS total) $(\mathrm{r}=0.646, \mathrm{p}<0.001)$ in addition to the physical $(\mathrm{r}=0.690, \mathrm{p}<0.001)$, cognitive $(r=0.451, p<0.001)$, and psychosocial $(r=0.616, p<0.001)$ subscales of the MFIS (Table 3). Furthermore, FSS scores demonstrated moderate correlation with quality of life (EQ-5D $\mathrm{D}_{\text {index }}: \mathrm{r}=-0.330, \mathrm{p}<0.001$; EQ-5D $\left.\mathrm{D}_{\text {status }}: \mathrm{r}=-0.415, \mathrm{p}<0.001\right)$, MS impact (MSIS-29 (physical): $r=0.547, p<0.001$; MSIS-29 (psychological): $r=0.466, p<0.001$ ), depression (HADS (depression): $r=0.364, p<0.001$ ), and cognition (MSNSQ: $r=0.321, p<0.001$ ), and weak correlation with anxiety (HADS (anxiety): $r=0.234, p<0.001)$ and sleep quality (PSQI: $\mathrm{r}=0.288, \mathrm{p}<0.001)$. There was no relationship between fatigue severity and time since diagnosis $(r=0.055, p=0.269)$ or fatigue severity and age $(r=0.096, p=0.051)$. 
There were few significant differences when comparing the strength of correlation between fatigue severity and clinical variables in the progressive MS and non-progressive MS populations. However, PDDS was moderately correlated with FSS scores in the nonprogressive MS population $(\mathrm{r}=0.335, \mathrm{p}<0.001)$ and demonstrated no association with fatigue severity in those with progressive MS $(r=0.092, p=0.335)$. For all other correlation coefficients, there was no difference between participants with progressive and nonprogressive forms of MS ( $\mathrm{p}>0.05)$.

Table 3 (near here)

\subsection{Correlation of fatigue impact with clinical variables}

Fatigue impact (MFIS (total)) demonstrated moderate to strong correlation with quality of life (EQ-5D $\mathrm{D}_{\text {index }}: \mathrm{r}=-0.542, \mathrm{p}<0.001$; EQ-5D $\left.\mathrm{D}_{\text {status }}: \mathrm{r}=-0.516, \mathrm{p}<0.001\right)$, MS impact (MSIS-29 (physical): $\mathrm{r}=0.660, \mathrm{p}<0.001$; MSIS-29 (psychological): $\mathrm{r}=0.721, \mathrm{p}<0.001$ ), anxiety (HADS (anxiety): $\mathrm{r}=0.442, \mathrm{p}<0.001$ ), depression (HADS (depression): $\mathrm{r}=0.559, \mathrm{p}<0.001$ ), cognition (MSNSQ: $r=0.665, p<0.001$ ), and sleep quality (PSQI: $r=0.438, p<0.001$ ) in the total study population (Table 4).

In the progressive MS population, age was negatively correlated with fatigue impact $(\mathrm{r}=$ $0.236, \mathrm{p}=0.014$ ), and HADS (anxiety) had a significantly stronger association with fatigue impact in comparison to those with non-progressive MS $(r=0.578$ vs. $0.388, p=0.037)$. Conversely, in the non-progressive MS population PDDS was moderately correlated with fatigue impact ( $\mathrm{r}=0.391, \mathrm{p}<0.001)$ and MSIS-29 (physical) was more strongly associated with fatigue impact in comparison to the progressive MS population $(\mathrm{r}=0.747 \mathrm{vs} .0 .599, \mathrm{p}=$ 0.02). All other correlation coefficients were comparable between the progressive and nonprogressive MS populations ( $\mathrm{p}>0.05)$.

\section{Table 4 (near here)}




\subsection{Variables predicting fatigue severity and impact}

In participants with progressive MS, MFIS (total) scores were the strongest predictor of fatigue severity $(\beta=0.816, p<0.001)$ (Table 5). In addition, MSIS-29 (psychological) $(\beta=$ $0.309, \mathrm{p}=0.053), \operatorname{HADS}$ (anxiety) $(\beta=-0.249, \mathrm{p}=0.05)$, and MSNSQ $(\beta=-0.290, \mathrm{p}<0.001)$ predicted an increase in fatigue severity; although MSIS-29 (psychological) and HADS (anxiety) did not reach the threshold for statistical significance $(\mathrm{p}<0.05)$. Overall, these variables accounted for $55.7 \%\left(\mathrm{R}^{2}=0.557\right)$ variance in $\mathrm{FSS}$ scores $(\mathrm{F}(4,78)=24.5$, $\mathrm{p}<0.001)$.

Similarly, fatigue impact was a strong predictor of FSS score in participants with nonprogressive MS $(\beta=0.566, p<0.001)$, while EQ-5D $D_{\text {index }}(\beta=0.117, p=0.086)$, MSIS-29 (physical) $(\beta=0.279, p=0.001)$, and MSNSQ $(\beta=-0.124, p=0.071)$ also contributed to the prediction of fatigue severity, with this model accounting for $43.3 \%\left(\mathrm{R}^{2}=0.433\right)$ variance in FSS scores $(\mathrm{F}(4,220)=42, \mathrm{p}<0.001)$. However, only the MFIS and MSIS-29 (physical) were significant predictors of FSS scores in this model $(\mathrm{p}<0.05)$.

\section{Table 5 (near here)}

FSS scores predicted fatigue impact in both the progressive MS $(\beta=0.428, p<0.001)$ and nonprogressive MS populations $(\beta=0.248, \mathrm{p}<0.001)$ (Table 6). In the progressive MS population, EQ-5D $D_{\text {index }}(\beta=-0.109, p=0.09), \operatorname{MSIS}-29$ (psychological) $(\beta=0.230, p=0.01)$, and MSNSQ $(\beta=0.349, \mathrm{p}<0.001)$ also predicted fatigue impact, accounting for $77 \%\left(\mathrm{R}^{2}=\right.$ 0.77 ) variance in MFIS (total) scores $(F(4,78)=65.4, p<0.001)$; whereas in participants with non-progressive MS, MSIS-29 (physical) $(\beta=0.305, \mathrm{p}<0.001)$, MSIS-29 (psychological) $(\beta$ $=0.269, \mathrm{p}<0.001)$, HADS (anxiety) $(\beta=-0.106, \mathrm{p}=0.032)$, and MSNSQ $(\beta=0.320$, $\mathrm{p}<0.001)$ accounted for $74.4 \%\left(\mathrm{R}^{2}=0.744\right)$ variance in MFIS (total) scores $(\mathrm{F}(5,219)=127$, $\mathrm{p}<0.001)$. 


\section{Table 6 (near here)}

\section{Discussion}

This large cross-sectional study found that fatigue was a prevalent symptom of MS, reported in $68.7 \%$ of the population. In addition, a higher proportion of participants with progressive MS (81.1\%) reported fatigue compared to those with non-progressive forms of MS $(64.1 \%)$, which confirms evidence from previous studies that fatigue is more prevalent amongst people with progressive forms of the disease $[13,19,23]$. Furthermore, in terms of the correlation between fatigue and clinical features of MS, both fatigue severity and impact were associated with higher levels of disability, poorer quality of life, greater depression and anxiety, and poor cognition and sleep quality. However, despite fatigue being more prevalent and severe in participants with progressive MS, the strength of association between fatigue severity/impact and the clinical features examined was generally comparable between the progressive MS and non-progressive MS populations.

Due to the different outcome measures and criteria used to define those with/without fatigue, it is difficult to directly compare the prevalence of fatigue in this progressive MS population with previously reported estimates of fatigue prevalence. However, the overall proportion of participants who reported fatigue in this study (68.7\%) is higher than other studies that defined fatigue using the same methods (FSS $\geq 5$ ), with estimates of prevalence reported as 54\% [21], 55\% [18], 58\% [17], and 65\% [8]. Heterogeneity in MS type between studies may account for some difference in the reported estimates of fatigue prevalence - for example, the study by Bakshi et al. [8] did not include people with PPMS, whereas the study by Andreasen et al. [17] only included people with RRMS. Nevertheless, despite differences in estimates of prevalence, this study confirms that fatigue is a common symptom of MS and highlights the need for effective fatigue management interventions - especially in those with progressive MS [54]. 
The exact mechanisms of fatigue in MS have still to be fully elucidated, but are likely to include issues with inflammation and function of demyelinated nerve pathways in addition to secondary factors (e.g. clinical features such as depression and disability) independent of the primary MS pathophysiology $[14,15]$. While several studies have investigated the association between fatigue and relevant outcomes, results remain equivocal with the presence and strength of association varying between studies. However, the findings from the overall study population confirm the results from previous studies that demonstrate fatigue is associated with physical [11, 13, 24], psychological [20, 21], and cognitive outcomes [17, 29] and, therefore, highlight the multifactorial and debilitating impact of fatigue in MS.

While causality cannot be inferred from these results, it is likely that fatigue is associated with these outcomes in a bi-directional relationship, as higher levels of fatigue could be the cause or consequence of impaired physical, cognitive, and psychological functioning [15]. For example, fatigue is often considered symptomatic of depression, although depression may develop as a result of fatigue and the resultant impact on daily living [20]. Similarly, mobility impairments may induce fatigue due to increased energy expenditure, whereas fatigue may limit mobility due to restrictions in physical activity [15]. Accordingly, longitudinal studies are required to establish the potential causal association between these outcomes and fatigue to improve fatigue management strategies for both progressive and non-progressive MS populations.

A novel finding of this study was that the strength of association between fatigue severity/impact and clinical features of MS were generally comparable between the progressive MS and non-progressive MS populations. However, there were a few exceptions as fatigue severity and impact were only correlated with disability in the non-progressive MS population, whereas fatigue impact was more strongly correlated with age and anxiety in the progressive MS population. Therefore, cognitive and psychological outcomes should be given greater prominence when designing and evaluating fatigue management interventions for people with progressive MS, as they were more strongly associated with fatigue in comparison to physical outcomes. Conversely, disability and physical outcomes may have greater importance when evaluating fatigue in a non-progressive MS population. 
Interestingly, in both the progressive and non-progressive MS populations, the clinical features examined in this study were more strongly associated with fatigue impact (MFIS) in comparison to fatigue severity (FSS). This result may suggest that the MFIS is a more sensitive measure of MS-related fatigue due to the multidimensional nature of fatigue and ceiling effect of the FSS $[38,55]$; however, it may also reflect the content validity of the MFIS and the limited ability to distinguish between global levels of function (e.g. physical, cognitive and psychosocial function) and the impact of fatigue on these domains [56]. Alternatively, outcomes other than those included in this study may be associated with the development and severity of fatigue - such as the primary disease mechanisms of MS. For example, it has been suggested that inflammation is associated with the development of fatigue, with levels of inflammatory biomarkers (interferon $\gamma$ and tumour necrosis factor $\alpha$ ) correlating with fatigue in MS $[57,58]$ - although this association may have limited relevance to progressive MS due to the absence of a marked inflammatory response $[59,60]$. Additionally, structural neurological damage - including cortical atrophy and grey matter lesions - and patterns of neural re-organisation have also been found to be associated with fatigue in MS [15, 57]. However, further longitudinal studies are required to determine the primary and secondary pathophysiological pathways involved in the development of MS related fatigue.

\subsection{Limitations}

Due to the cross-sectional nature of this study, it was not possible to determine causality in the relationship between fatigue and the selected clinical and demographic variables. In addition, although the FSS and MFIS were selected to independently measure the severity and impact of fatigue, the strong association between these outcome measures may suggest they measure related aspects of fatigue. Furthermore, as data were collected through an open online survey, our study population may have been biased towards people experiencing fatigue, and was limited to those who were able to access the internet which potentially excluded those with more severe disabilities (for example, advanced cognitive, visual or physical impairments). In addition, the study design dictated that self-reported outcome measures were used to assess all clinical features; therefore, although the MSNSQ has limited reliability in measuring cognitive function (particularly in people with depression and cognitive impairment) [48], it was included in this study as it could be feasibly used as a selfreported outcome measure and provides a quick and valid estimation of cognitive function 
[47]. However, the online nature of this study enabled a large international population to be recruited, and although MS diagnosis and type were self-reported, the participant demographics of this study sample were representative of a typical MS population [61, 62]. Lastly, as the number of potentially eligible participants was unknown, it was not possible to determine the survey response rate.

\section{Conclusions}

To our knowledge, this was the first study to compare the association between fatigue severity/impact and selected clinical and demographic variables in people with progressive and non-progressive forms of MS. This study confirmed that fatigue is a common symptom of MS, and that fatigue is more prevalent and severe amongst those with progressive MS. In addition, fatigue severity and impact were found to correlate with quality of life, MS impact, depression, anxiety, cognition, and sleep quality, and the strength of these relationships were similar in participants with progressive and non-progressive forms of MS. Therefore, this study highlights the multifactorial nature of fatigue and the importance of considering these outcomes as potential mediator or moderator variables when comprehensively designing and evaluating interventions aimed at improving fatigue. Furthermore, these associations may underline potential causal pathways of fatigue in both progressive and non-progressive forms of MS, and justifies the need for longitudinal assessment to explore the mechanisms of MSrelated fatigue.

Declaration of conflicting interests: The Authors declare that there is no conflict of interest Funding: This research did not receive any specific grant from funding agencies in the public, commercial, or not-for-profit sectors. 
[1] Multiple Sclerosis Council for Clinical Practice Guidelines. Fatigue and multiple sclerosis: Evidence-based management strategies for fatigue in multiple sclerosis.

Washington D.C.: Paralyzed Veterans of America. 1998.

[2] Bakshi R. Fatigue associated with multiple sclerosis: diagnosis, impact and management. Mult Scler 2003;9(3):219-227.

[3] Janardhan V, Bakshi R. Quality of life in patients with multiple sclerosis: The impact of fatigue and depression. J Neurol Sci 2002;205(1):51-58.

[4] Moore P, Harding KE, Clarkson H, Pickersgill TP, Wardle M, Robertson NP. Demographic and clinical factors associated with changes in employment in multiple sclerosis. Mult Scler 2013;19(12):1647-1654.

[5] Krupp LB, Alvarez LA, LaRocca NG, Scheinberg LC. Fatigue in multiple sclerosis. Arch Neurol 1988;45(4):435-437.

[6] Fisk JD, Pontefract A, Ritvo PG, Archibald CJ, Murray TJ. The impact of fatigue on patients with multiple sclerosis. Can J Neurol Sci 1994;21(1):9-14.

[7] Ford H, Trigwell P, Johnson M. The nature of fatigue in multiple sclerosis. J Psychosom Res 1998;45(1):33-38.

[8] Bakshi R, Shaikh ZA, Miletich RS, Czarnecki D, Dmochowski J, Henschel K, et al. Fatigue in multiple sclerosis and its relationship to depression and neurologic disability. Mult Scler 2000;6(3):181-185.

[9] Lerdal A, Celius EG, Moum T. Fatigue and its association with sociodemographic variables among multiple sclerosis patients. Mult Scler 2003;9(5):509-514.

[10] Lerdal A, Celius EG, Krupp L, Dahl AA. A prospective study of patterns of fatigue in multiple sclerosis. Eur J Neurol 2007;14(12):1338-1343.

[11] Hadjimichael O, Vollmer T, Oleen-Burkey M, North American Research Committee on Multiple Sclerosis. Fatigue characteristics in multiple sclerosis: the North American Research Committee on Multiple Sclerosis (NARCOMS) survey. Health Qual Life Outcomes 2008;6:1-11.

[12] Zajicek JP, Ingram WM, Vickery J, Creanor S, Wright DE, Hobart JC. Patient-orientated longitudinal study of multiple sclerosis in south west England (The South West Impact of Multiple Sclerosis Project, SWIMS) 1: protocol and baseline characteristics of cohort. BMC Neurol 2010;10:1-11.

[13] Fiest KM, Fisk JD, Patten SB, Tremlett H, Wolfson C, Warren S, et al. Fatigue and Comorbidities in Multiple Sclerosis. Int J MS Care 2016;18(2):96-104.

[14] Langeskov-Christensen M, Bisson EJ, Finlayson ML, Dalgas U. Potential pathophysiological pathways that can explain the positive effects of exercise on fatigue in multiple sclerosis: A scoping review. J Neurol Sci 2017;373:307-320. 
[15] Kos D, Kerckhofs E, Nagels G, D'hooghe MB, Ilsbroukx S. Origin of Fatigue in Multiple Sclerosis: Review of the Literature. Neurorehabil Neural Repair 2008;22(1):91-100.

[16] Kroencke DC, Lynch SG, Denney DR. Fatigue in multiple sclerosis: relationship to depression, disability, and disease pattern. Mult Scler 2000;6(2):131-136.

[17] Andreasen AK, Spliid PE, Andersen H, Jakobsen J. Fatigue and processing speed are related in multiple sclerosis. Eur J Neurol 2010;17(2):212-218.

[18] Tellez N, Rio J, Tintore M, Nos C, Galan I, Montalban X. Fatigue in multiple sclerosis persists over time: a longitudinal study. J Neurol 2006;253(11):1466-1470.

[19] Johansson S, Ytterberg C, Hillert J, Widen Holmqvist L, von Koch L. A longitudinal study of variations in and predictors of fatigue in multiple sclerosis. $\mathrm{J}$ Neurol Neurosurg Psychiatry 2008;79(4):454-457.

[20] Brown RF, Valpiani EM, Tennant CC, Dunn SM, Sharrock M, Hodgkinson S, et al. Longitudinal assessment of anxiety, depression, and fatigue in people with multiple sclerosis. Psychol Psychother 2009;82(1):41-56.

[21] Wood B, van der Mei IA, Ponsonby AL, Pittas F, Quinn S, Dwyer T, et al. Prevalence and concurrence of anxiety, depression and fatigue over time in multiple sclerosis. Mult Scler 2013;19(2):217-224.

[22] Iriarte J, Subira ML, Castro P. Modalities of fatigue in multiple sclerosis: correlation with clinical and biological factors. Mult Scler 2000;6(2):124-130.

[23] Mills RJ, Young CA. The relationship between fatigue and other clinical features of multiple sclerosis. Mult Scler 2011;17(5):604-612.

[24] Learmonth YC, Dlugonski D, Pilutti LA, Sandroff BM, Klaren R, Motl RW. Psychometric properties of the Fatigue Severity Scale and the Modified Fatigue Impact Scale. J Neurol Sci 2013;331:102-107.

[25] Flachenecker P, Kümpfel T, Kallmann B, Gottschalk M, Grauer O, Rieckmann P, et al. Fatigue in multiple sclerosis: a comparison of different rating scales and correlation to clinical parameters. Mult Scler 2002;8(6):523-526.

[26] Strober LB, Arnett PA. An examination of four models predicting fatigue in multiple sclerosis. Arch Clin Neuropsychol 2005;20(5):631-646.

[27] Stanton BR, Barnes F, Silber E. Sleep and fatigue in multiple sclerosis. Mult Scler 2006;12(4):481-486.

[28] Nociti V, Losavio FA, Gnoni V, Losurdo A, Testani E, Vollono C, et al. Sleep and fatigue in multiple sclerosis: A questionnaire-based, cross-sectional, cohort study. J Neurol Sci 2017;372:387-392.

[29] Heesen C, Schulz KH, Fiehler J, Von der Mark U, Otte C, Jung R, et al. Correlates of cognitive dysfunction in multiple sclerosis. Brain Behav Immun 2010;24(7):1148-1155. 
[30] Amato MP, Zipoli V, Portaccio E. Multiple sclerosis-related cognitive changes: a review of cross-sectional and longitudinal studies. J Neurol Sci 2006;245(1-2):41-46.

[31] Marrie RA, Reider N, Cohen J, Trojano M, Sorensen PS, Cutter G, et al. A systematic review of the incidence and prevalence of sleep disorders and seizure disorders in multiple sclerosis. Mult Scler 2015;21(3):342-349.

[32] Harris PA, Taylor R, Thielke R, Payne J, Gonzalez N, Conde JG. Research electronic data capture (REDCap)--a metadata-driven methodology and workflow process for providing translational research informatics support. J Biomed Inform 2009;42(2):377-381.

[33] Hohol MJ, Orav EJ, Weiner HL. Disease steps in multiple sclerosis: a simple approach to evaluate disease progression. Neurology 1995;45(2):251-255.

[34] Schwartz CE, Vollmer T, Lee H. Reliability and validity of two self-report measures of impairment and disability for MS. North American Research Consortium on Multiple Sclerosis Outcomes Study Group. Neurology 1999;52(1):63-70.

[35] Krupp LB, LaRocca NG, Muir-Nash J, Steinberg AD. The fatigue severity scale. Application to patients with multiple sclerosis and systemic lupus erythematosus. Arch Neurol 1989;46(10):1121-1123.

[36] Kos D, Kerckhofs E, Nagels G, D'Hooghe BD, Duquet W, Duportail M, et al. Assessing fatigue in multiple sclerosis: Dutch modified fatigue impact scale. Acta Neurol Belg 2003;103(4):185-191.

[37] Rietberg MB, Van Wegen EE, Kwakkel G. Measuring fatigue in patients with multiple sclerosis: reproducibility, responsiveness and concurrent validity of three Dutch self-report questionnaires. Disabil Rehabil 2010;32(22):1870-1876.

[38] Amtmann D, Bamer AM, Noonan V, Lang N, Kim J, Cook KF. Comparison of the Psychometric Properties of Two Fatigue Scales in Multiple Sclerosis. Rehabil Psychol 2012;57(2):159-166.

[39] Kos D, Kerckhofs E, Carrea I, Verza R, Ramos M, Jansa J. Evaluation of the Modified Fatigue Impact Scale in four different European countries. Mult Scler 2005;11(1):76-80.

[40] Hobart J, Lamping D, Fitzpatrick R, Riazi A, Thompson A. The Multiple Sclerosis Impact Scale (MSIS-29): a new patient-based outcome measure. Brain 2001;124(5):962-973.

[41] McGuigan C, Hutchinson M. The multiple sclerosis impact scale (MSIS-29) is a reliable and sensitive measure. J Neurol Neurosurg Psychiatry 2004;75(2):266-269.

[42] Gray O, McDonnell G, Hawkins S. Tried and tested: the psychometric properties of the multiple sclerosis impact scale (MSIS-29) in a population-based study. Mult Scler 2009;15(1):75-80.

[43] EuroQol Group. EuroQol--a new facility for the measurement of health-related quality of life. Health Policy 1990;16(3):199-208. 
[44] Dolan P. Modeling valuations for EuroQol health states. Med Care 1997;35(11):10951108.

[45] Zigmond AS, Snaith RP. The hospital anxiety and depression scale. Acta Psychiatr Scand 1983;67(6):361-370.

[46] Honarmand K, Feinstein A. Validation of the Hospital Anxiety and Depression Scale for use with multiple sclerosis patients. Mult Scler 2009;15(12):1518-1524.

[47] Benedict RH, Munschauer F, Linn R, Miller C, Murphy E, Foley F, et al. Screening for multiple sclerosis cognitive impairment using a self-administered 15-item questionnaire. Mult Scler 2003;9(1):95-101.

[48] Benedict RH, Cox D, Thompson LL, Foley F, Weinstock-Guttman B, Munschauer F. Reliable screening for neuropsychological impairment in multiple sclerosis. Mult Scler 2004;10(6):675-678.

[49] Benedict RH, Duquin JA, Jurgensen S, Rudick RA, Feitcher J, Munschauer FE, et al. Repeated assessment of neuropsychological deficits in multiple sclerosis using the Symbol Digit Modalities Test and the MS Neuropsychological Screening Questionnaire. Mult Scler 2008;14(7):940-946.

[50] Buysse DJ, Reynolds CF,3rd, Monk TH, Berman SR, Kupfer DJ. The Pittsburgh Sleep Quality Index: a new instrument for psychiatric practice and research. Psychiatry Res 1989;28(2):193-213.

[51] Carpenter JS, Andrykowski MA. Psychometric evaluation of the Pittsburgh Sleep Quality Index. J Psychosom Res 1998;45(1):5-13.

[52] Hinkle DE, Wiersma W, Jurs SG. Applied statistics for the behavioral sciences. Houghton Mifflin, Boston. 1988.

[53] Fisher RA. Frequency Distribution of the Values of the Correlation Coefficient in Samples from an Indefinitely Large Population. Biometrika 1915;10(4):507-521.

[54] James Lind Alliance. MS Priority Setting Partnership. National Institute for Health Research Evaluation: James Lind Allinace. 2013.

[55] Tellez N, Rio J, Tintore M, Nos C, Galan I, Montalban X. Does the Modified Fatigue Impact Scale offer a more comprehensive assessment of fatigue in MS? Mult Scler 2005;11(2):198-202.

[56] Hobart J, Cano S, Baron R, Thompson A, Schwid S, Zajicek J, et al. Achieving valid patient-reported outcomes measurement: a lesson from fatigue in multiple sclerosis. Mult Scler 2013;19(13):1773-1783.

[57] Induruwa I, Constantinescu CS, Gran B. Fatigue in multiple sclerosis - A brief review. J Neurol Sci 2012;323:9-15. 
[58] Patejdl R, Penner IK, Noack TK, Zettl UK. Multiple sclerosis and fatigue: A review on the contribution of inflammation and immune-mediated neurodegeneration. Autoimmun Rev 2016;15(3):210-220.

[59] Mahad D, Trapp B, Lassmann H. Pathological mechanisms in progressive multiple sclerosis. Lancet Neurol 2015;14(2):183-193.

[60] Lassmann H. Targets of therapy in progressive MS. Mult Scler 2017;23(12):1593-1599.

[61] Compston A, Coles A. Multiple sclerosis. The Lancet 2008;372(9648):1502-1517.

[62] Mackenzie IS, Morant SV, Bloomfield GA, Macdonald TM, O'Riordan J. Incidence and prevalence of multiple sclerosis in the UK 1990-2010: a descriptive study in the General Practice Research Database. J Neurol Neurosurg Psychiatry 2014;85(1):76-84. 
Table 1 Participant demographics

\begin{tabular}{|c|c|c|c|c|}
\hline & $\begin{array}{l}\text { Total population } \\
\qquad(\mathrm{n}=412)\end{array}$ & $\begin{array}{l}\text { Progressive MS } \\
\text { (SPMS, n=74; } \\
\text { PPMS, } n=37 \text {; total, } \\
\text { n=111) }\end{array}$ & $\begin{array}{c}\text { Non-progressive } \\
\text { MS (RRMS, } \mathrm{n}=291 \\
\text { Benign MS, } \mathrm{n}=2 ; \\
\text { unknown, } \mathrm{n}=8 \text {; total, } \\
\mathrm{n}=301 \text { ) }\end{array}$ & $\mathbf{p}$ \\
\hline $\begin{array}{l}\text { Age (years), mean } \pm \\
\text { SD (range) }\end{array}$ & $46 \pm 11.5(22-79)$ & $56 \pm 8.9(30-79)$ & $42 \pm 10.1(22-69)$ & $<0.001$ \\
\hline $\begin{array}{l}\text { Time since } \\
\text { diagnosis (years), } \\
\text { mean } \pm \text { SD (range) }\end{array}$ & $9.6 \pm 8.6(0-44)$ & $15.4 \pm 10.6(0-44)$ & $7.4 \pm 6.5(0-36)$ & $<0.001$ \\
\hline $\begin{array}{l}\text { PDDS, mean } \pm \text { SD } \\
\text { (range) }\end{array}$ & $3.1 \pm 2.3(0-8)$ & $5.6 \pm 1.4(2-8)$ & $2.2 \pm 1.9(0-7)$ & $<0.001$ \\
\hline \multicolumn{5}{|l|}{ Sex, \% (n) } \\
\hline Female & $81.3 \%(335)$ & $77.5 \%(86)$ & $82.7 \%$ (249) & \multirow{2}{*}{0.225} \\
\hline Male & $18.7 \%(77)$ & $22.5 \%(25)$ & $17.3 \%(52)$ & \\
\hline \multicolumn{5}{|l|}{ Work status, \% (n) } \\
\hline Working & $47.1 \%(194)$ & $18 \%(20)$ & $57.8 \%(174)$ & \multirow[t]{2}{*}{$<0.001$} \\
\hline Not working & $52.9 \%(218)$ & $82 \%(91)$ & $42.2 \%(127)$ & \\
\hline \multicolumn{5}{|l|}{$\begin{array}{l}\text { Highest level of } \\
\text { education, } \%(n)\end{array}$} \\
\hline University or college & $69.7 \%(287)$ & $66.7 \%(74)$ & $70.8 \%(213)$ & \multirow{4}{*}{0.576} \\
\hline $\begin{array}{l}\text { Trade/vocational } \\
\text { training }\end{array}$ & $10.4 \%(43)$ & $9 \%(10)$ & $11 \%(33)$ & \\
\hline High school & $19.2 \%(79)$ & $23.4 \%(26)$ & $17.6 \%(53)$ & \\
\hline $\begin{array}{l}\text { Did not complete } \\
\text { high school }\end{array}$ & $0.7 \%(3)$ & $0.9 \%(1)$ & $0.7 \%(2)$ & \\
\hline
\end{tabular}


Table 2 Prevalence of fatigue and response to questionnaires

\begin{tabular}{|c|c|c|c|c|}
\hline & $\begin{array}{c}\text { Total population } \\
\qquad(\mathrm{n}=412)\end{array}$ & $\begin{array}{c}\text { Progressive MS } \\
(\mathrm{n}=111)\end{array}$ & $\begin{array}{c}\text { Non-progressive } \\
\text { MS }(n=301)\end{array}$ & $\mathbf{p}$ \\
\hline $\begin{array}{l}\text { Fatigue } \\
\text { prevalence* }(95 \% \\
\text { CI) }\end{array}$ & $\begin{array}{r}68.7 \%(64.1-73) \\
(\mathrm{n}=283)\end{array}$ & $\begin{array}{r}81.1 \%(72.8-87.3) \\
(\mathrm{n}=90)\end{array}$ & $\begin{array}{r}64.1 \%(58.6-69.3) \\
(\mathrm{n}=193)\end{array}$ & 0.010 \\
\hline FSS & $5.4 \pm 1.4(\mathrm{n}=412)$ & $5.6 \pm 1.3(\mathrm{n}=111)$ & $5.2 \pm 1.4(\mathrm{n}=301)$ & 0.012 \\
\hline MFIS (total) & $54.6 \pm 16(\mathrm{n}=385)$ & $56.5 \pm 15.8(\mathrm{n}=107)$ & $53.9 \pm 16.1(\mathrm{n}=278)$ & 0.149 \\
\hline MFIS (physical) & $25.5 \pm 7.3(\mathrm{n}=385)$ & $27.8 \pm 6.1(n=107)$ & $24.7 \pm 7.5(\mathrm{n}=278)$ & $<0.001$ \\
\hline MFIS (cognitive) & $23.7 \pm 9.1(\mathrm{n}=385)$ & $23 \pm 10.3(n=107)$ & $24 \pm 8.6(n=278)$ & 0.371 \\
\hline $\begin{array}{l}\text { MFIS } \\
\text { (psychosocial) }\end{array}$ & $5.4 \pm 2(n=385)$ & $5.7 \pm 1.8(\mathrm{n}=107)$ & $5.2 \pm 2(\mathrm{n}=278)$ & 0.009 \\
\hline EQ-5D $\mathbf{D}_{\text {index }}$ & $\begin{array}{r}0.51 \pm 0.34 \\
(\mathrm{n}=375)\end{array}$ & $0.33 \pm 0.36(\mathrm{n}=105)$ & $0.58 \pm 0.3(\mathrm{n}=270)$ & $<0.001$ \\
\hline EQ-5D $D_{\text {status }}$ & $\begin{array}{r}56.5 \pm 22.7 \\
(\mathrm{n}=372)\end{array}$ & $49.3 \pm 24(n=104)$ & $59.3 \pm 21.5(\mathrm{n}=268)$ & $<0.001$ \\
\hline $\begin{array}{l}\text { MSIS-29 } \\
\text { (physical) }\end{array}$ & $\begin{array}{r}61.5 \pm 20.1 \\
(\mathrm{n}=365)\end{array}$ & $76.1 \pm 16.6(\mathrm{n}=102)$ & $55.9 \pm 18.5(\mathrm{n}=263)$ & $<0.001$ \\
\hline $\begin{array}{l}\text { MSIS-29 } \\
\text { (psychological) }\end{array}$ & $27.8 \pm 8.9(\mathrm{n}=365)$ & $27.8 \pm 9.2(\mathrm{n}=102)$ & $27.7 \pm 8.8(n=263)$ & 0.924 \\
\hline HADS (anxiety) & $8.9 \pm 4.7(n=357)$ & $8.7 \pm 5(n=99)$ & $8.9 \pm 4.6(n=258)$ & 0.667 \\
\hline $\begin{array}{l}\text { HADS } \\
\text { (depression) }\end{array}$ & $7.9 \pm 4.3(\mathrm{n}=357)$ & $9.34 \pm 4.5(\mathrm{n}=99)$ & $7.3 \pm 4.1(n=258)$ & $<0.001$ \\
\hline MSNSQ & $\begin{array}{r}30.4 \pm 14.6 \\
(\mathrm{n}=347)\end{array}$ & $28.8 \pm 15.3(n=97)$ & $31 \pm 14.3(n=250)$ & 0.200 \\
\hline PSQI & $9.5 \pm 4.1(\mathrm{n}=308)$ & $9.2 \pm 3.9(\mathrm{n}=83)$ & $9.6 \pm 4.2(\mathrm{n}=225)$ & 0.416 \\
\hline
\end{tabular}

Abbreviations: FSS, Fatigue Severity Scale; HADS, Hospital Anxiety and Depression Scale; MFIS, Modified Fatigue Impact Scale; MS, Multiple Sclerosis; MSIS-29, Multiple Sclerosis Impact Scale-29; MSNSQ, Multiple Sclerosis Neuropsychological Screening Questionnaire; PSQI, Pittsburgh Sleep Quality Index

Values reported as mean \pm SD unless otherwise specified; values in brackets indicate the number of participants who completed each questionnaire

*Percentage of participants who reported FSS $\geq 5$ 
Table 3 Correlation (r) of the Fatigue Severity Scale with clinical and demographic features in the progressive MS and non-progressive MS population

\section{FSS}

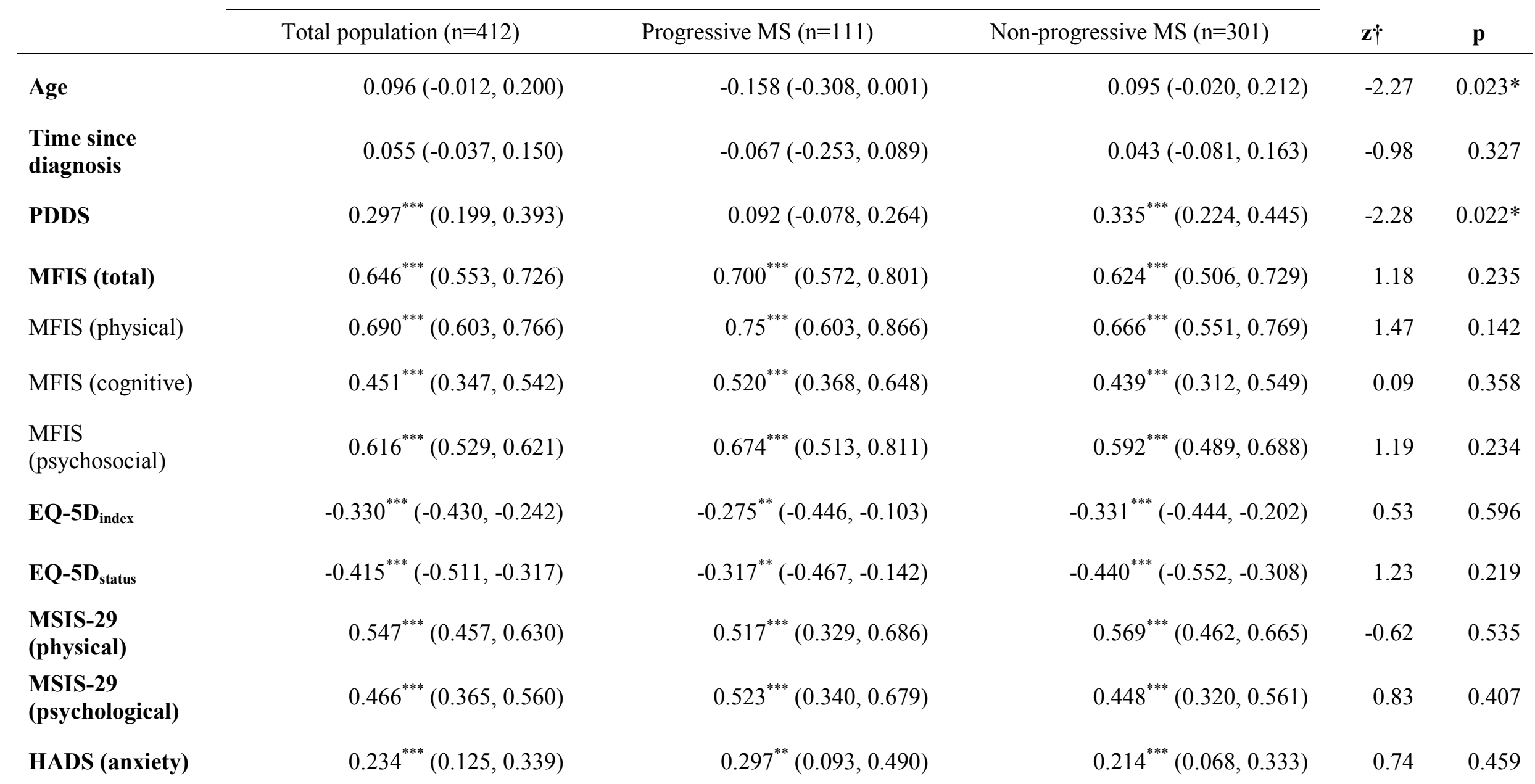




\begin{tabular}{|c|c|c|c|c|c|}
\hline $\begin{array}{l}\text { HADS } \\
\text { (depression) }\end{array}$ & $0.364^{* * *}(0.257,0.457)$ & $0.328^{* *}(0.115,0.527)$ & $0.357^{* * *}(0.236,0.470)$ & -0.27 & 0.787 \\
\hline MSNSQ & $0.321^{* * *}(0.217,0.423)$ & $0.350^{* * *}(0.199,0.484)$ & $0.325^{* * *}(0.192,0.445)$ & 0.23 & 0.818 \\
\hline PSQI & $0.288^{* * *}(0.177,0.399)$ & $0.374^{* * *}(0.183,0.544)$ & $0.268^{* * *}(0.139,0.393)$ & 0.91 & 0.363 \\
\hline
\end{tabular}

Abbreviations: FSS, Fatigue Severity Scale; HADS, Hospital Anxiety and Depression Scale; MFIS, Modified Fatigue Impact Scale; MS, Multiple Sclerosis; MSIS-29, Multiple Sclerosis Impact Scale-29; MSNSQ, Multiple Sclerosis

Neuropsychological Screening Questionnaire; PDDS, Patient Determined Disease Steps; PSQI, Pittsburgh Sleep Quality Index

Values reported as Pearson correlation coefficients $(95 \% \mathrm{CI})$

$* \mathrm{p}<0.05 ; * * \mathrm{p}<0.01 ; * * * \mathrm{p}<0.001$; otherwise value is not significant $(\mathrm{p}>0.05)$

$\dagger \mathrm{z}$ score for the comparison of correlation coefficients between Progressive MS and Non-progressive MS populations 
Table 4 Correlation (r) of the Modified Fatigue Impact Scale with clinical and demographic features in the progressive MS and non-progressive MS population

\section{MFIS}

\begin{tabular}{|c|c|c|c|c|c|}
\hline & Total population $(n=385)$ & Progressive MS (n=107) & Non-progressive MS (n=278) & $\mathbf{z} \dagger$ & $\mathbf{p}$ \\
\hline Age & $-0.007(-0.128,0.101)$ & $-0.236^{*}(-0.422,-0.062)$ & $0.006(-0.130,0.139)$ & -2.14 & $0.032 *$ \\
\hline $\begin{array}{l}\text { Time since } \\
\text { diagnosis }\end{array}$ & $0.056(-0.053,0.152)$ & $0.007(-0.184,0.189)$ & $0.040(-0.090,0.158)$ & -0.29 & 0.772 \\
\hline PDDS & $0.291^{* * *}(0.189,0.389)$ & $0.090(-0.073,0.268)$ & $0.391^{* * *}(0.280,0.495)$ & -2.80 & $0.005 * *$ \\
\hline FSS & $0.646^{* * *}(0.553,0.726)$ & $0.700^{* * *}(0.572,0.801)$ & $0.624^{* * *}(0.506,0.729)$ & 1.18 & 0.235 \\
\hline EQ-5D index $_{\text {}}$ & $-0.542^{* * *}(-0.609,-0.471)$ & $-0.485^{* * *}(-0.613,-0.337)$ & $-0.585^{* * *}(-0.654,-0.525)$ & 1.21 & 0.226 \\
\hline EQ-5D status $_{\text {s }}$ & $-0.516^{* * *}(-0.587,-0.439)$ & $-0.490^{* * *}(-0.619,-0.346)$ & $-0.526^{* * *}(-0.605,-0.432)$ & 0.42 & 0.675 \\
\hline $\begin{array}{l}\text { MSIS-29 } \\
\text { (physical) }\end{array}$ & $0.660^{* * *}(0.592,0.718)$ & $0.599^{* * *}(0.431,0.729)$ & $0.747^{* * *}(0.689,0.757)$ & -2.33 & $0.020 *$ \\
\hline $\begin{array}{l}\text { MSIS-29 } \\
\text { (psychological) }\end{array}$ & $0.721^{* * *}(0.668,0.775)$ & $0.752^{* * *}(0.626,0.836)$ & $0.711^{* * *}(0.651,0.769)$ & 0.75 & 0.453 \\
\hline HADS (anxiety) & $0.442^{* * *}(0.345,0.525)$ & $0.578^{* * *}(0.408,0.711)$ & $0.388^{* * *}(0.280,0.490)$ & 2.09 & $0.037 *$ \\
\hline $\begin{array}{l}\text { HADS } \\
\text { (depression) }\end{array}$ & $0.559^{* * *}(0.478,0.624)$ & $0.562^{* * *}(0.391,0.693)$ & $0.561^{* * *}(0.476,0.642)$ & 0.01 & 0.992 \\
\hline MSNSQ & $0.665^{* * *}(0.600,0.722)$ & $0.702^{* * *}(0.587,0.786)$ & $0.659^{* * *}(0.579,0.724)$ & 0.66 & 0.509 \\
\hline PSQI & $0.438^{* * *}(0.339,0.530)$ & $0.465^{* * *}(0.266,0.617)$ & $0.434^{* * *}(0.314,0.538)$ & 0.30 & 0.764 \\
\hline
\end{tabular}


Abbreviations: FSS, Fatigue Severity Scale; HADS, Hospital Anxiety and Depression Scale; MFIS, Modified Fatigue Impact Scale; MS, Multiple Sclerosis; MSIS-29,

Multiple Sclerosis Impact Scale-29; MSNSQ, Multiple Sclerosis Neuropsychological Screening Questionnaire; PDDS, Patient Determined Disease Steps; PSQI,

Pittsburgh Sleep Quality Index

Values reported as Pearson correlation coefficients $(95 \% \mathrm{CI})$

$* \mathrm{p}<0.05 ; * * \mathrm{p}<0.01 ; * * * \mathrm{p}<0.001 ;$ otherwise value is not significant $(\mathrm{p}>0.05)$

$\dagger \mathrm{z}$ score for the comparison of correlation coefficients between Progressive MS and Non-progressive MS populations 
Table 5 Results of regression analysis indicating the variables which predicted Fatigue Severity Scale scores in the progressive MS and non-progressive MS populations

\section{FSS}

Variables

\begin{tabular}{llll}
$\mathrm{R}^{2}$ & $\mathrm{~b}(\mathrm{SE})$ & $\beta$ & $\mathrm{p}$ \\
\hline
\end{tabular}

(a)

$0.557^{*}$

Constant

$1.810(0.403) \quad . \quad<0.001$

MFIS (total)

$0.690(0.010) \quad 0.816<0.001$

MSIS-29

(psychological)

$0.045(0.023) \quad 0.309 \quad 0.053$

HADS (anxiety)

$\begin{array}{lll}-0.066(0.033) & -0.249 & 0.05\end{array}$

MSNSQ

$\begin{array}{lll}-0.025(0.010) & -0.290 \quad 0.013\end{array}$

(b)

$0.433 \dagger$

Constant

MFIS (total)

EQ-5D index $_{\text {in }}$

MSIS-29 (physical)

MSNSQ

$\begin{array}{rrr}1.378(0.478) & \cdot & 0.004 \\ 0.051(0.008) & 0.566 & <0.001 \\ 0.556(0.323) & 0.117 & 0.086 \\ 0.022(0.006) & 0.279 & 0.001 \\ -0.012(0.007) & -0.124 & 0.071\end{array}$

Abbreviations: FSS, Fatigue Severity Scale; HADS, Hospital Anxiety and Depression Scale; MFIS, Modified Fatigue Impact Scale; MS, Multiple Sclerosis; MSIS-29, Multiple Sclerosis Impact Scale-29; MSNSQ, Multiple Sclerosis Neuropsychological Screening Questionnaire

(a), Progressive MS; (b), Non-progressive MS

* $\mathrm{F}(4,78)=24.5, \mathrm{p}<0.001$

$\dagger \mathrm{F}(4,220)=42, \mathrm{p}<0.001$ 
Table 6 Results of regression analysis indicating the variables which predicted Modified Fatigue Impact Scale scores in the progressive MS and non-progressive MS populations

\begin{tabular}{|c|c|c|c|c|}
\hline \multirow[b]{2}{*}{ Variables } & \multicolumn{4}{|c|}{ MFIS } \\
\hline & $\mathrm{R}^{2}$ & $\mathrm{~b}(\mathrm{SE})$ & $\beta$ & $\mathrm{p}$ \\
\hline (a) & $0.770 *$ & & & \\
\hline Constant & & $8.089(4.562)$ & . & 0.08 \\
\hline EQ-5D index & & $-4.822(2.808)$ & -0.109 & 0.09 \\
\hline $\begin{array}{l}\text { MSIS-29 } \\
\text { (psychological) }\end{array}$ & & $0.395(0.150)$ & 0.230 & 0.01 \\
\hline MSNSQ & & $0.360(0.078)$ & 0.349 & $<0.001$ \\
\hline FSS & & $5.071(0.755)$ & 0.428 & $<0.001$ \\
\hline (b) & $0.744 \dagger$ & & & \\
\hline Constant & & $2.984(2.287)$ & & 0.193 \\
\hline MSIS-29 (physical) & & $0.265(0.046)$ & 0.305 & $<0.001$ \\
\hline $\begin{array}{l}\text { MSIS-29 } \\
\text { (psychological) }\end{array}$ & & $0.492(0.120)$ & 0.269 & $<0.001$ \\
\hline HADS (anxiety) & & $-0.371(0.172)$ & -0.106 & 0.032 \\
\hline MSNSQ & & $0.359(0.049)$ & 0.320 & $<0.001$ \\
\hline FSS & & $2.780(0.469)$ & 0.248 & $<0.001$ \\
\hline
\end{tabular}

Abbreviations: FSS, Fatigue Severity Scale; HADS, Hospital Anxiety and Depression Scale; MFIS, Modified Fatigue Impact Scale; MS, Multiple Sclerosis; MSIS-29, Multiple Sclerosis Impact Scale-29; MSNSQ, Multiple Sclerosis Neuropsychological Screening Questionnaire

(a), Progressive MS; (b), Non-progressive MS

* $\mathrm{F}(4,78)=65.4, \mathrm{p}<0.001$

$\dagger \mathrm{F}(5,219)=127, \mathrm{p}<0.001$ 